Running head: COGNITIVE SKILLS TRANSFER IN BILITERACY DEVELOPMENT

Transfer of Reading-Related Cognitive Skills in Learning to Read Chinese (L1)

and English (L2) among Chinese Elementary School Children

Yuen-Ching Keung \& Connie Suk-Han Ho

The University of Hong Kong

Date of first submission: 17 October 2007

Address for correspondence:

Connie Suk-Han Ho, Department of Psychology, The University of Hong Kong, Pokfulam Road, Hong Kong

E-mail: shhoc@hkucc.hku.hk

Fax: (852) 28583518

Telephone: (852) 22415652 


\begin{abstract}
This study investigated transfer of reading-related cognitive skills between learning to read Chinese (L1) and English (L2) among Chinese children in Hong Kong. Fifty-three Grade 2 students were tested on word reading, phonological, orthographic and rapid naming skills in Chinese (L1) and English (L2). The major findings were: (a) significant correlations between Chinese and English measures in phonological awareness and rapid naming, but not in orthographic skills; (b) significant unique contribution of Chinese and English rapid naming skills and English rhyme awareness for predicting Chinese word reading after controlling for all the Chinese and English cognitive measures; (c) significant unique contribution of English phonological skills and Chinese orthographic skills (a negative one) for predicting English word reading after controlling for all the English and Chinese cognitive measures; and (d) significant unique contribution of Chinese rhyme awareness for predicting English phonemic awareness. These findings provide initial evidence that developing reading-related cognitive skills in English may have facilitative effects on Chinese word reading development. They also suggest that Chinese orthographic skills or tactics may not be helpful for learning to read English words among ESL learners; and that Chinese rhyme awareness facilitates the development of English phonemic awareness which is an essential skill predicting ESL learning.
\end{abstract}

Key words: Cognitive skills transfer; phonological awareness; orthographic skills; rapid automatized naming; biliteracy development 


\section{Transfer of Reading-Related Cognitive Skills in Learning to Read Chinese (L1) and English (L2) among Chinese Elementary School Children}

Reading is a complex process involving different mental operations in which readingrelated cognitive skills play an important role in these operations. For many years, research studies on reading development have focused on the acquisition of first language: what are the developmental trajectories or patterns as well as underlying cognitive processes or skills contributing to reading development? Earlier reading acquisition models such as those of Chall (1983), Ehri (1995, 1999), and Frith (1985), were developed to understand reading development of English as the first language. These models provide a basis for the study of other alphabetic scripts sharing similar writing systems (e.g., Carillo, 1994; Cossu, Shankweiler, Liberman, Tola, \& Katz, 1988; Sebastian-Galles \& Parreno-Vacchiano, 1995; Sprenger-Charolles, Siegel, \& Bonnet, 1998; Wimmer \& Hummer, 1990).

Later, cross-cultural studies begin to investigate the reading development of nonalphabetic scripts, such as Chinese and Japanese, as compared to alphabetic scripts (e.g., Akita \& Hatano, 1999; Hanley, Tzeng, \& Huang, 1999; Ho \& Bryant, 1997a). A large body of research studies have explored whether phonological processing skills play the same important role as in learning to read English or other alphabetic scripts (e.g., Lundberg, 1994; Oney \& Durgunoglu, 1997). Some other researchers are interested to explore whether there are other cognitive skills, besides phonological processing skills, also play an important role in first language acquisition in different orthographies (e.g., Casalis \& Louis-Alexandre, 2000; Cho \& Chen, 1999; Lepola, Poskiparta, Laakkonen, \& Niemi, 2005; Manis, Seidenberg, \& Doi, 1999; Mann, 2000; Sprenger-Charolles, Siegel, Bechennec, \& Serniclaes, 2003; Wagner \& Barker, 1994; Wolf, Vellutino, \& Gleason, 1998).

Another line of research on reading development extends the study from first language to second language acquisition. One of the key focuses is to explore whether and to 
what extent acquisition of second language shares the same developmental patterns and involves the same cognitive skills, processes and development as acquisition of first language. Some studies focus on examining how one's first language development influences his or her ability to acquire a second language and this relates to the issue of cognitive skills transfer from first language (L1) to second language (L2). These studies have taken a somewhat similar approach as their earliest predecessors: with a focus on the acquisition of English as a second language for children with other alphabetic scripts as their first language such as Hebrew, Spanish and French and studying the transfer of phonological skills between them (Comeau, Cormier, Grandmaison, \& Lacroix, 1999; Durgunoglu, Nagy, \& HancinBhatt, 1993; Geva, Wade-Woolley, \& Shany, 1997; Gottardo, 2002).

In more recent years, some studies explore reading development of English as a second language for children with non-alphabetic scripts such as Japanese and Chinese as their first language (Akamatsu, 1999; Chow, McBride-Chang, \& Burgess, 2005; Geva et al., 1997; Wang, Park, \& Lee, 2006; Wang, Perfetti, \& Liu, 2005). These research studies begin to examine cognitive skills transfer between a non-alphabetic script to an alphabetic script, and involve studying not just phonological skills transfer but also orthographic skills transfer (Wang et al., 2005). Rapid automatized naming, however, is less examined in these studies, despite that it has been repeatedly found to associate with reading acquisition irrespective of the orthography in which children learn to read (Manis et al., 1999; Wolf \& Bowers, 1999).

Nevertheless, until now, not many studies have been devoted to understanding the nature of cognitive skills transfer between learning to read Chinese (L1) and English (L2). It was still unclear whether any specific Chinese cognitive skills (namely phonological skills, orthographic skills, rapid automatized naming skills) that have been established to be essential in learning to read Chinese (L1) would have positive skills transfer to the development of corresponding English reading-related cognitive skills which may be further 
leveraged on to promoting learning to read English (L2). The present study aimed to fill this gap by examining two different levels of transfer: one is the transfer that occurs among the reading-related cognitive skills in learning to read Chinese (L1) and English (L2) among Chinese elementary school children, and the other is the one that occurs from reading-related cognitive skills to reading outcomes across these two languages, Chinese (L1) and English (L2).

In the following paragraphs, we will review theories related to L2 reading models and discuss the cognitive skills essential for learning to read Chinese and English.

\section{Early Theories of L2 Reading Models}

Theories of $\mathrm{L} 2$ reading models have evolved from a simple $\mathrm{R} 1=\mathrm{R} 2$ theory to the now more sophisticated perspective to investigate the transfer of cognitive skills between L1 and L2. The R1=R2 theory states that there is no significant difference in the cognitive process of learning to read a language between native speakers and second language learners. Some aspects of the processes may be used less or may operate more slowly by second language learners (Fitzgerald, 1995). Yet these differences do not render the need for a separate theory explaining the learning of second language reading. In other words, considerations such as transfer of skills and teaching approaches of second languages are ignored by this simplistic theory. This model was criticised by many researchers, most notably Bernhardt (1991), of its disregard of the importance and possible benefits of the characteristics of one's mother tongue and his or her learning experiences, skills and strategies.

Cummins (1991) introduced the idea of "interdependence" in second language acquisition. His developmental interdependence hypothesis states that the skills developed in L1 will transfer to L2, if and only if a linguistic threshold competence is attained in L2. This theoretical construct of threshold refers to general language proficiency rather than literacy (i.e. threshold hypothesis). In other words, the learning of L2 is at least partly dependent on 
the cognitive skills developed through the learning of L1. While, Cummins's theory put emphasis on the importance of the interdependence of learning to read L1 and L2, some theorists (e.g. Geva \& Ryan, 1993) regarded his theory as too general, failing to elaborate the specific nature of interdependence, and to take account of individual differences in cognitive ability.

\section{Transfer of Cognitive Skills in Reading Development}

Some researchers have adopted the component skills approach proposed by Carr and Levy (1990) to understand the transfer of cognitive skills between learning to read the first and second languages. This approach analyzes reading as a complex information-processing system involving a number of related but separate mental operations. Individual operations serve distinct functions yet interact together to acquire a visually presented language in the activity of reading. Transferable skills depend on the similarities and differences of L1 and L2 to be learnt since some languages emphasize more of a specific skill than others (Geva \& Siegel, 2000).

Transfer of cognitive skills in learning to read L1 and L2 refers to cognitive skills acquired in L1 reading development that can be leveraged on to promoting or facilitating L2 reading development, and vice versa. This is also commonly known as positive transfer. While, should the cognitive skills acquired in L1 reading development hinder the learning to read L2, and vice versa, then it would be considered as negative transfer of skills or interference. In the following paragraphs, we will briefly review existing key research studies that have employed the transfer of cognitive skills approach in learning to read first and second languages.

Recent research studies provide support to the view that phonological skills transfer exists within alphabetic languages and across different orthographic systems. In particular, phonological skills transfer was found in more than a handful of alphabetic languages. For 
example, Durgunoglu et al. (1993) investigated factors influencing English (L2) word identification performance of Spanish-speaking beginning readers. Their findings revealed that readers' levels of phonological awareness and word recognition in Spanish (L1) predicted their English (L2) word and pseudoword recognition performance. Similarly, D'Angiulli, Siegel and Serra (2001) investigated the English-Italian interdependence related to phonological processing among Canadian-Italian bilingual children aged 9-14 attending grades 4-8. Their findings suggest that exposure to a language with more predictable grapheme-phoneme correspondences, such as Italian, may enhance phonological skills in English.

There were also examples of phonological skills transfer across different orthographic systems, such as Chinese and English. For example, Gottardo, Yan, Siegel, \& Wade-Woolley (2001) found significant correlations between Chinese rhyme detection and English phonological and reading measures in Cantonese-English bilingual children. Chinese rhyme detection in particular was predictive of English word reading after controlling the effects of age and education in respective languages. Pang (2004) has also provided some evidence to bi-directional transfer of phonological skills between English (L1) and Chinese (L2) in Singaporean English-Chinese bilingual and biliterate $2^{\text {nd }}$ and $3^{\text {rd }}$ grade students. Similarly, Chow et al. (2005) also demonstrated that phonological awareness in Chinese helps concurrent and subsequent English language acquisition in Hong Kong Chinese kindergarteners learning to read English as a second language. These findings support the language-universal characteristics of phonological skills that are intrinsic to children's language acquisition across orthographies. In addition, phonological transfer appears not to be restricted to languages with similar structures.

Some recent research studies also explore the possible transfer of orthographic skills across different orthographic systems. In a study of Korean-English biliteracy acquisition 
(Wang et al., 2006), findings suggest that there is limited facilitation of orthographic skills in the case of two orthographic systems that share the alphabetic principles but differ in visual forms. However, the area remains largely uncharted. There is also little understanding of possible transfer of other cognitive skills, such as rapid naming, that are shown to have positive relations with reading abilities. In this regard, the present study was conducted aiming to examine the cross-orthography transfer of different reading-related cognitive skills, including not only phonological awareness, but also orthographic skills and rapid automatized naming, related to learning to read Chinese (L1) and English (L2).

The Role of Phonological Awareness, Orthographic Skills, and Rapid Automatized

\section{Naming in Learning to Read English and Chinese}

Learning to read is a complex process involving the integration of many cognitive skills. Among them, phonological awareness, orthographic skills and rapid automatized naming are basic reading-related cognitive skills for learning to read both English and Chinese. In the following paragraphs, we will provide an overview of the roles and significance of these three types of cognitive skills in learning to read English and Chinese.

\section{Phonological Awareness}

Phonological awareness is the awareness that words are composed of speech sounds. According to Goswami and Byrant (1990), there are at least three possible forms of phonological awareness: syllables, intra-syllabic units (e.g. onsets and rhymes), and phonemes. It is argued that the ability to link phonemes to letters is both a prerequisite for and a consequence of learning to read (Yopp, 1992). Phonological awareness has been found to be a good predictor of reading performance across alphabetic languages (Goswami \& Bryant, 1990; Rack, Snowling, \& Olson, 1992; Shankweiler \& Fowler, 2004; Torgesen, 1999). It is nevertheless a necessary but not sufficient condition for learning to read. Other cognitive 
skills such as phonological memory, naming speed, orthographic knowledge, and morphological awareness are also essential.

On the other hand, Chinese is a monosyllabic script, which is very different from English - a multiphonemic script. The Chinese language has a simpler syllable structure than English. A Chinese character is a single syllable with two apparent levels of phonological awareness: the larger unit of syllable, and a smaller unit of subsyllable (e.g. onset, rhyme, body or coda). There is growing evidence to support that phonological awareness does have a role in learning to read Chinese (Ho \& Byrant, 1997a; Hu \& Catts, 1998; Huang \& Hanley, 1994; McBride-Chang \& Ho, 2000; So \& Siegel, 1997).

In the present study, it was of interest to examine whether and to what extent possible transfer of phonological awareness would take place at the two different levels (i.e., among phonological awareness across Chinese (L1) and English (L2), as well as from phonological awareness to word reading outcomes across these two languages) for Chinese-speaking children when learning to read Chinese as native language and English as a second language. Specifically, in the investigation of the transfer occurring among phonological awareness across Chinese (L1) and English (L2), it was of interest to examine whether transfer of phonological awareness would be possible not only at a parallel subsyllabic rhyme level across Chinese (L1) and English (L2) as previous research studies have shown, but also would occur from a subsyllabic rhyme level of Chinese (L1) to a deeper and finest level of phonemic awareness in English (L2). There were two rationales behind this investigation: a) research in English reading development shows that one's phonological awareness at the subsyllabic level can predict one's success in phonemic awareness; and b) previous studies on phonological transfer between Chinese and English provide evidence to the transfer of phonological awareness at the parallel subsyllabic level across Chinese and English, though 
yet to show possible transfer from Chinese subsyllabic to English phonemic levels (e.g., Huang \& Hanley, 1994; Gottardo et al., 2001; Pang, 2004).

It is therefore worthwhile to confirm the direct relationship between rhyme awareness in Chinese (L1) and phonemic awareness in English (L2) among Hong Kong elementary school children learning to read Chinese (L1) and English (L2). The significance of this investigation is to provide evidence to the perspective that training Chinese children's subsyllabic rhyme awareness in their native language (i.e., Chinese) may facilitate their acquisition of phonemic awareness in English (L2) - an essential skill in learning to read English (L2).

\section{Orthographic Skills}

In comparison to phonological awareness, the conceptualization of orthographic skills is more complicated and controversial. Researchers have yet to agree on a definition (Wagner \& Barker, 1994). In relation to alphabetic scripts, some researchers define orthographic skills as "the ability to represent the unique array of letters that defines a printed word, as well as general attributes of the writing system such as sequential dependencies, structural redundancies, letter position frequencies.” (Vellutino, Scanlon, \& Tanzman, 1994, p. 314). Other researchers however do not perceive orthographic skills as totally unrelated to phonological processing with respect to alphabetic scripts. Goswami (1990) postulates that "an orthographic form is not simply a visually-similar sequence of letters: it is the identity of the letters in the sentence and their systematic relationship to sound which is important" (p. 324,). The above definitions suggest that orthographic skills in English involve some wordspecific memory and implicit knowledge for intraword letter patterns learnt through exposure to print. In addition, it may also be related to phonological processing especially among regular English words with consistent grapheme-phoneme correspondence. 
Unlike the English writing system, Chinese is a morphosyllabic script (Leong \& Joshi, 1997) that is visually and orthographically more complex. About $90 \%$ of Chinese characters are ideophonetic compounds. That is, each of which comprising a semantic radical and a phonetic radical. The semantic radical reveals something about the meaning of a character, while the phonetic radical is indicative of the pronunciation of a character. The radicals often occupy habitual positions in a character. Recent research findings suggest that this kind of knowledge of a radical's specific information, position, and function contributes to Chinese word reading development (Ho, Yau, \& Au, 2003).

Yet, little is known about whether transfer of orthographic skills is likely to occur at the two different levels (i.e. among orthographic skills across Chinese (L1) and English (L2), as well as from orthographic skills to word reading outcomes across these two languages). Given that Chinese and English are two very different orthographies as mentioned above, learning to read Chinese and English respectively involves very specific declarative knowledge. For example, English language learners have to become familiar with the permissible letter patterns that might be facilitated by their knowledge of the graphemephoneme conversion rules of regular English words as well as implicit knowledge of irregular words. While, Chinese language learners have to be aware of the roles of semantic and phonetic radicals in Chinese characters and become familiar with their different permissible positions in a character.

The present study has adapted Perfetti's operation to measure orthographic skills as the ability of a reader to recognize permissible orthographic structure in English and Chinese (Perfetti, 1984). Specifically, permissible orthographic structure in Chinese refers to permissible radical combinations and permissible orthographic structure in English refers to permissible letter patterns. It was expected to find minimal transfer of orthographic skills between learning to read Chinese and English, given that the underlying skills are more word- 
specific memory and knowledge of orthographic structure, rather than some general visual and analytical skills.

\section{Rapid Automatized Naming}

An earlier conceptualization considered rapid automatized naming to be one type of phonological processing skills. According to Wagner \& Torgesen (1987), deficit in rapid naming skills was just another manifestation of deficit in phonological recoding in lexical access, as suggested in the phonological-core deficit view of dyslexia. Nevertheless, the proposal of the double-deficit hypothesis of dyslexia by Wolf and Bowers (1999) gives rise to an alternative conceptualization of rapid automatized naming. According to Wolf and Bowers, rapid automatized naming should be regarded as a distinct and separate source of readingrelated cognitive skills different from phonological skills as shown in their research findings. In their conceptualization, rapid automatized naming involves "both processing speed and the integration of an ensemble of lower level visual perceptual processes and higher level cognitive and linguistic subprocesses" (p. 418).

Research studies so far have provided sufficient evidence to support rapid automatized naming as a core cognitive skill for learning to read English (Bowers \& NewbyClark, 2002; Kail \& Hall, 1994; Manis, Doi, \& Bhadha, 2000; Manis et al., 1999) as well as learning to read Chinese (Ho, Chan, Tsang \& Lee, 2002; Ho, Chan, Tsang, Lee \& Luan, 2004; Ho \& Lai, 1999). For example, Manis et al. (2000) have identified that digit and letter naming are powerful predictors of reading. Bowers \& Newby-Clark (2002) further postulate that naming speed plays a significant role in lexical or whole word processing. Through efficient recognition of orthographic units, it facilitates word recognition. While, in a number of studies conducted by Ho and her colleagues, they found that Chinese dyslexic children exhibited naming-speed deficits in their learning to read Chinese like their alphabetic counterparts (e.g., Ho et al., 2002; Ho et al., 2004; Ho \& Lai, 1999). 
Rapid automatized naming in Chinese (L1) and English (L2) involves very similar processes: a) visual attentional process, b) access of overlearnt code, c) activation of the stored phonological label, and d) motoric activation leading to articulation. Global processing speed is critical to ensure these processes to operate smoothly and integrate with one another efficiently. On this basis, the present study expected transfer of rapid automatized naming to take place between learning to read Chinese (L1) and English (L2).

Until now, transfer of rapid automatized naming between Chinese (L1) and English (L2) is a topic less explored in the field of biliteracy acquisition. Nonetheless, this was another research question that the present study aimed to answer. Results of this transfer investigation may help early identification of at-risk ESL learners for intervention. Early rapid automatized naming in L1 may serve as a reliable indicator of potential reading disability among ESL children despite of the absence of fully developed proficiency in L2.

\section{Aims of the Present Study}

The present study aimed to investigate two different levels of transfer: (1) whether any possible transfer of phonological awareness, orthographic skills or rapid automatized naming would occur across Chinese (L1) and English (L2); and (2) to what extent phonological awareness, orthographic knowledge and rapid automatized naming in Chinese (L1) and English (L2) would predict word reading performance in Chinese as a native language and English as a second language.

As stated in the literature review above, positive transfer at the two different levels was expected to occur in phonological awareness and rapid automatized naming between learning to read Chinese (L1) and English (L2), but not in orthographic skills. It was also expected that there would be phonological skills transfer from Chinese rhyme level to English phonemic level.

\section{Method}




\section{Participants}

There were altogether 53 Hong Kong Chinese Primary 2 students participating in the present study (including 27 boys and 26 girls). Primary 2 students were selected as the target participants as they were expected to have achieved some basic reading levels in both languages, which made possible the present investigation of cognitive skills transfer between learning to read Chinese (L1) and English (L2).

All the participants had Cantonese as their native and home language. They were recruited from two local primary schools. The two schools were representative of typical mainstream primary schools in Hong Kong, with the characteristics that a) Cantonese was the medium of instruction in all subjects except English Language, b) around 4-5 hours each school devoted to English learning at school, and c) phonics was not adopted as the primary teaching approach of English Language. According to the schools, they were ESL beginning learners.

Age of the participants ranged from 7 years 6 months to 9 years 3 months (with a mean age of 8 years 2 months and a standard deviation of 5 months). In addition, all of them had normal nonverbal intelligence as measured by the Raven's Standard Progressive Matrices. The IQ of the participants ranged from 92 to 135 (with a mean IQ of 110.5 and a standard deviation of 9.9).

\section{Materials and Procedures}

A total of 9 tasks were administered to the participants in a group and an individual session at their own schools. The children were given an intelligence test, two phonological tasks, and two orthographic tasks in the group session, and a reading task, a phonological task, and two naming speed tasks in the individual session.

\section{Nonverbal Intelligence}


The present study used the Raven's Standard Progressive Matrices with local norms established in 1986 to estimate the participants' nonverbal intelligence. The full version consisted of five sets: A, B, C, D, and E, tapping one's ability to see the nature of relationships within patterns. Each set contained 12 items arranged in an increasing order of difficulty. Each item consisted of a pattern with a missing piece and the participants were required to choose from 6 to 8 alternatives the one that completed the target pattern. In this study, the full version (sets A to E) was administered to participants of 8 years 6 months or older, whereas the short form (sets A to C) was administered to participants who were younger than 8 years 6 months old.

\section{Literacy Tasks}

Chinese Word Reading. The present study used the Chinese Word Reading for Junior Primary School Children, a test that was developed and standardized by the Hong Kong Education Department in 1988 to measure the children's Chinese word reading performance. The word list consisted of 65 Chinese two-character words arranged in an increasing order of difficulty. The participants were asked to read aloud the two-character words one by one. One point was given for reading each two-character word correctly. The task was discontinued when the participant failed to read 10 consecutive words.

English Word Reading. We have developed an English word reading task to measure the participants' English word reading performance. This graded word reading task was developed based on the consultation of some local English textbooks of Grade 1 to Grade 4 levels and local English teachers, and results of a pilot study. They were key words included in the local English textbooks for school children at Grade 1 to Grade 4 levels in Hong Kong. The word list included a variety of words: a) different parts of speech (e.g., noun, pronoun, verb, adjective, adverb, preposition, etc.), b) different word lengths (i.e., ranging from 3 up to 9 letters), and c) different syllable counts (i.e., ranging from a single up to 3 syllables count). 
The final word list consisted of 65 words arranged in an increasing order of difficulty. One point was given for reading each English word correctly.

\section{Phonological Tasks}

Chinese Rhyme Detection. This task aimed at tapping one's sensitivity to rhyme, an important aspect of phonological awareness in Chinese (Ho \& Bryant, 1997b). There were a total of 3 practice and 18 test trials. In each trial, the participants heard three Chinese syllables through a CD player. The tone of the three stimuli in each item was kept the same. The syllables were names of common objects and pictures of these objects were printed on an answer sheet. The experimenter held up the answer sheet in front of the class to point at the corresponding pictures along with the presentation of syllables. The participants were asked to put a cross on the answer to indicate the syllable that did not rhyme with the other two syllables. For example, in an item: [fo]2 (fire), [gau]2 (dog), [so]2 (lock), the children needed to identify [gau]2 (dog) as the odd one.

English Rhyme Detection. The English Rhyme Detection task was a parallel measure of the Chinese Rhyme Detection task. There were a total of 3 practice and 18 test trials. They were all single-syllable words. Majority of them were words having a CVC structures while some were words with a consonant clusters. They were not necessarily familiar words for the participants. The procedure of this task was the same as that of the Chinese rhyme detection task. Again the children were required to identify the odd one out.

English Initial Phoneme Deletion. This task was a measure of the children's phonemic sensitivity. There were 3 practice and 20 test trials. All of them except the last item were single-syllable words, with majority of them having a CVC structure. They were not necessarily familiar words for the participants. In each trial, the experimenter read aloud an English word and asked the participants to say the remainder of the given word after taking out the initial phoneme. 


\section{Orthographic Tasks}

Chinese Lexical Decision. The Lexical Decision Subtest of the Hong Kong Test of Specific Learning Difficulties in Reading and Writing (Ho, Chan, Tsang \& Lee, 2000) was used to assess the participants' knowledge of Chinese character structure. There were a total of 60 characters, in which 30 of them were rare Chinese characters 30 were noncharacters. Each rare character or noncharacter was comprised of two components arranged in a left-right structure. Rare characters were real Chinese characters of low frequencies at the Primary school levels. Each noncharacter was constructed by combining a semantic radical and a phonetic radical in their illegal positions, or by combining two semantic radicals or two phonetic radicals that were not possible in Chinese characters. The participants were required to cross out the noncharacters. According to Ho and her colleagues (2000), Spearman-Brown split-half reliability for the age groups of 7 years 1 month to 9 years 6 months ranged between .63 to .79 .

English Lexical Decision. We developed an English lexical decision task to assess the participants' knowledge of permissible letter patterns for English words. There were 3 practice and 18 test items. In each item, there were three words: two of them were real English words much beyond their grade level to ensure that the participants did not know them, and one was a nonword in English with illegal letter pattern. There were three types of illegal letter patterns in this task: a) illegal initial 2-letter combination (e.g., words starting with letters “Cc”, “Nr”, “Fm”, “Gg”, “Sd”, “Ls”, “Lp”, “Tl”, “Tm”), b) illegal final 2-letter combination (e.g., words ending with letters “dd", "kn”, “kk”, “tm”, “bl”, “pn”, “hh", "td”), and c) other illegal letters combination in words (e.g., words ending with letters combination of "ae", words in which short vowel followed by single "k", words with 3 vowels or 3 consonants in straight, words without any vowel). The participants were asked to put a cross 
on the nonword in each item. Spearman-Brown split-half reliability was .51. By dropping item 1: base, botw, bead, the reliability improved to .61 .

\section{Rapid Automaticized Naming Tasks}

Two picture rapid naming tasks were used to measure the participants' naming speed in both Chinese and English. In both tasks, there were five single-syllable picture stimuli (flower ([faa $] 1)$, ball ([bo]1), car ([ce]1), fire ([fou $] 1)$, cap ([mou 6$)$ for the Chinese task; boy, eye, cup sun, dog for the English task) printed eight times in fixed random orders on an A4 paper. The participants were asked to name the pictures as fast and as accurately as possible from left to right row by row. The participants were asked to read the list twice, and the score of each task was the average naming latency of the two trials.

\section{Results}

Table 1 summarizes the mean scores, standard deviations, and reliability coefficients of the tasks administered to the participants in the present study. Internal reliability and distribution of the scores generally looked good.

\section{Partial Correlations among Various Literacy and Cognitive Tasks}

Table 2 shows the partial correlation coefficients among the various literacy and cognitive tasks after controlling for the effects of age and IQ. Three key observations were made to examine: (1) whether specific Chinese cognitive skills were correlated with corresponding English cognitive skills, (2) what Chinese and English cognitive skills were correlated with Chinese word reading, and (3) what English and Chinese cognitive skills were correlated with English word reading.

First, Chinese rhyme detection correlated significantly with English rhyme detection and English initial phoneme deletion (all $\underline{\mathrm{r}} \mathrm{s}>.30$, all $\underline{\mathrm{ps}}<.05$ ); and Chinese rapid naming and English rapid naming were highly correlated with each other $(\mathrm{r}=.67, \mathrm{p}<.001)$. However, Chinese lexical decision and English lexical decision did not correlate significantly. These 
results provided initial evidence to support for the possible transfer of phonological skills and rapid automatized naming skills between learning to read Chinese (L1) and English (L2), but not for the transfer of orthographic skills.

Second, among the three Chinese cognitive skills, only Chinese rapid naming correlated significantly with Chinese word reading $(r=-.44, p=.001)$. Among the four English cognitive skills, English rapid naming, rhyme detection, and phoneme deletion correlated significantly with Chinese word reading (all /rs $/>.32$, all $\mathrm{ps}<.05$ ).

Third, among the four English cognitive skills, English initial phoneme deletion, rhyme detection, and lexical decision correlated significantly with English word reading (all $\underline{\mathrm{rs}}>.28$, all $\mathrm{ps}<.05)$. Among the three Chinese cognitive skills, both Chinese rhyme detection and rapid naming correlated significantly with English word reading (all $\underline{\mathrm{rs}}>.27$, all ps $<.05)$, while Chinese lexical decision only marginally correlated with English word reading $(r=-.27, p=.054)$.

\section{Predicting Word Reading Performance in Chinese as a Native Language}

In this section, multiple regression analyses were conducted to investigate to what extent phonological awareness, orthographic skills and rapid automatized naming in Chinese (L1) and English (L2) predicted word reading performance in Chinese as a native language. It was of an interest to find out as well whether the English cognitive skills explained a significant amount of variance in Chinese word reading after Chinese cognitive skills were taken into account.

Hierarchical regression analysis was first conducted to examine whether Chinese rapid naming would explain a significant amount of variance in the prediction of Chinese word reading as a native language. Results of the first three steps of the regression analysis (see Table 3) confirmed that Chinese (L1) rapid naming predicted a significant unique amount of variance in Chinese (L1) word reading even when the effects of age, IQ and two 
other Chinese (L1) cognitive tasks were controlled $\left(\Delta \mathrm{R}^{2}=.14, \underline{\mathrm{p}}<.01\right)$. However, the prediction was not significant when Chinese lexical decision or rhyme detection was entered as the third step. These results have provided support for the unique role of Chinese rapid naming in early reading development of Chinese among elementary students.

Following this, Table 3 also shows that English rapid naming and rhyme detection had significant unique contribution to Chinese word reading even when all the Chinese and other English cognitive skills were controlled $\left(\Delta \mathrm{R}^{2}=.06, \underline{\mathrm{p}}<.05\right)$. This suggests that some English (L2) cognitive skills, such as English rapid naming and rhyme detection, as developed and acquired in learning to read English as a second language can have unique contribution to the children's learning to read Chinese as a native language.

\section{Predicting Word Reading Performance in English as a Second Language}

In this section, multiple regression analyses were conducted to investigate to what extent phonological awareness, orthographic skills and rapid automatized naming in Chinese (L1) and English (L2) predicted word reading performance in English as a second language. Similarly, we examined whether the Chinese cognitive skills explained a significant amount of variance in English word reading after English cognitive skills were taken into account.

Hierarchical regression analysis was conducted to examine whether English rhyme detection and initial phoneme deletion would explain a significant amount of variance in the prediction of English word reading as a second language, and that English initial phoneme deletion would be a better predictor than English rhyme detection. Results of the first four steps of the regression analysis (see Table 4) confirmed that each of the two English (L2) phonological tasks predicted a significant unique amount of variance in English (L2) word reading even when the effects of age, IQ and two other English (L2) cognitive tasks were controlled $\left(\Delta \mathrm{R}^{2}=.07, \underline{\mathrm{p}}<.05\right.$ for English rhyme detection, and $\Delta \mathrm{R}^{2}=.37, \underline{\mathrm{p}}<.001$ for English initial phoneme deletion). However, the prediction was not significant when English 
rapid naming or lexical decision was entered as the fourth step. These results have provided strong evidence of the unique role of English phonological awareness, especially that of phonemic awareness, in early reading development of English as a second language among Chinese elementary students.

Following this, Table 4 also shows that Chinese lexical decision had significant negative contribution to English word reading even when all the English and Chinese cognitive skills were controlled $\left(\Delta \mathrm{R}^{2}=.06, \mathrm{p}<.01\right)$. This suggests possible negative transfer between orthographic skills in Chinese (L1) and reading in English (L2).

\section{Possible Phonological Skills Transfer from Subsyllablic Level in Chinese (L1) to Phonemic}

\section{Level in English (L2)}

The investigation extended to explore whether there was possible direct phonological transfer from Chinese subsyllabic rhyme level to English phonemic level. Table 5 shows that Chinese rhyme detection had significant unique contribution to English initial phoneme deletion when the effects of age, IQ, and English rhyme detection were controlled $\left(\Delta \mathrm{R}^{2}=.14\right.$, $\mathrm{p}<.01)$

\section{Discussion}

Research aims of the present study were to investigate the two different levels of transfer: (a) any possible transfer of phonological awareness, orthographic skills or rapid automatized naming from Chinese (L1) to English (L2); and (b) to what extent phonological awareness, orthographic skills and rapid automatized naming in Chinese (L1) and English (L2) predicting Chinese (L1) and English (L2) word reading, respectively.

First, the present study has found significant partial correlations between Chinese and English measures in phonological awareness and rapid naming after controlling age and IQ, but not in orthographic skills. These results confirm our expectation that transfer of phonological skills and rapid automatized naming skills is likely to take place in learning to 
read Chinese (L1) and English (L2), but not for orthographic skills. The positive transfer of phonological skills and rapid naming from L1 to L2 suggests that these skills are likely universal and easily transferable across languages, whereas orthographic skills are scriptspecific and less likely to be transferred.

Second, with respect to the results examining to what extent cognitive skills in Chinese (L1) and English (L2) would predict Chinese (L1) word reading, it was found that Chinese rapid naming, English rapid naming and English rhyme detection had significant unique contribution to Chinese word reading over that of age, IQ, and other cognitive measures.

Third, with respect to the results examining to what extent cognitive skills in Chinese (L1) and English (L2) would predict English (L2) word reading, it was found that English phonological skills (including rhyme detection and initial phoneme deletion) significantly predicted English (L2) word reading. Interestingly, Chinese orthographic skills also had significant negative contribution to English word reading over that of age, IQ, and all the English and Chinese cognitive measures.

\section{Chinese and English Cognitive Skills Predictive of Chinese Word Reading}

Results of the present study have shown that Chinese rapid naming, English rapid naming, and English rhyme detection predicted a significant unique amount of variance in Chinese (L1) word reading, but Chinese lexical decision or Chinese rhyme detection did not. The present findings have provided some initial evidence that developing reading-related cognitive skills in English (L2) may have facilitative effects on Chinese (L1) word reading development and that rapid automatized naming serves as a core cognitive skill for learning to read Chinese especially for Hong Kong readers. This may be explained by the fact that the skill of learning the arbitrary associations of script and sound in Chinese is partially tapped by the RAN tasks and the look-and-say method of instruction in Hong Kong encourages rote 
memory of Chinese characters, a skill very much like automatic naming of visually presented materials in the RAN tasks.

The nonsignificant contribution of Chinese lexical decision to Chinese (L1) word reading is unexpected. The Chinese lexical decision task on knowledge of character structure appears to be somewhat too easy for the participants (with average correct rate of $85 \%$ ) and more complicated orthographic skills (e.g., skills on processing the sound and meaning of phonetic and semantic radicals respectively) may be more predictive of Chinese word reading for the second graders who have learned to read Chinese since age 3.

It is also interesting to find that English rhyme awareness predicted Chinese word reading but Chinese rhyme awareness did not. In fact the two rhyme tasks were quite similar in terms of test materials and procedures, except that the English syllables were much less familiar to the children than were the Chinese syllables. We believe that memory of unfamiliar syllables in addition to rhyme awareness may be an essential skill for second graders when more and more new Chinese characters are learned.

\section{English and Chinese Cognitive Skills Predictive of English Word Reading}

Results of the present study have shown that the two English phonological tasks (phoneme deletion and rhyme detection) each predicted a significant unique amount of variance in English (L2) word reading, but English orthographic skill or rapid naming did not. These findings provide more evidence to existing research findings that phonemic processing skills are important not just in learning to read English as a first language (see Ehri, Nunes, Schuster, Yaghoub-Zadeh, \& Shanahan, 2001) but also as a second language among beginning ESL learners with L1 as Chinese, a non-alphabetic script (e.g., Chow et al., 2005; McBride-Chang \& Ho, 2005; McBride-Chang \& Treiman, 2003).

The finding of nonsignificant contribution of English orthographic skills to English (L2) word reading is consistent with other findings in local ESL reading development studies 
(e.g. Yeung, 2006) in which English (L2) phonological skills were shown to be of particular importance to English (L2) reading development among younger ESL learners in Hong Kong while the significance of English (L2) visual-orthographic skills only emerged among older ESL learners.

A possible explanation for the nonsignificant contribution of English rapid naming to English word reading is that rapid naming associates more with identification of moderate and high frequency words (Bowers, 1993; Bowers \& Swanson, 1991). However, the words in our English reading task appeared to be too difficult for early ESL learners. We suggest that rapid naming in L2 may only predict L2 word reading when learners have reached a minimum threshold of fluency in the second language.

The present findings also show a negative transfer of Chinese orthographic skills to English (L2) word reading. It is possible that Hong Kong elementary school children while developing their phonological awareness in English (L2) would also use some Chinese orthographic tactics to assist their learning of English words. However, these skills may be counter-effective when children learn to read more and more novel English words. This point will be further elaborated in the next section.

\section{Transfer of Orthographic Skills}

The present study has shown that there was no significant correlation in orthographic skills between Chinese (L1) and English (L2). Such findings are consistent to existing knowledge of orthographic transfer, in which orthographic skills are postulated as skills very specific to its particular orthography. Thus, Chinese (L1) orthographic skills are not expected to facilitate the development of English (L2) orthographic skills or English word reading given that Chinese (a morphosyllabic script) and English (a morphophonemic script) are two very different orthographies. If children attempt to use Chinese orthographic skills to assist 
learning to read English words, this may even create interference (i.e., negative transfer) to their reading development in English.

To explain why there is no significant transfer of orthographic skills between Chinese (L1) and English (L2), and even negative transfer between Chinese orthographic skills and English (L2) word reading, we suggest that: First, as mentioned earlier, orthographic skills in Chinese and English are very different. Development of Chinese orthographic skills involves the mastery of the large number of recurring stroke-patterns (radicals), the positional frequencies (left/right and top/bottom) and functions (as phonological and semantic cues) of these radicals, and the correct visual-spatial combinations of the radicals. The relationship between orthographic units and sound in Chinese is a part-whole derived phonology, i.e., using only the phonetic radical to derive at the sound of the whole character. On the other hand, the orthographic pattern of an English word is visually simple and sequential, and it is assembled rather than part-whole phonology in English. Second, with regard to the negative transfer between Chinese orthographic skills and English word reading, the present findings suggest that application of orthographic skills or tactics in Chinese may interfere with word learning in English. Possible explanations are that the visual-spatial skills acquired in recognizing Chinese characters may not facilitate memory of letter sequences. In addition, the part-whole derived phonology encourages character decoding at the syllabic level in Chinese, whereas the assembled phonology requires word decoding at the phonemic level in English. Therefore, applying the orthographic tactics in Chinese to learning of English words would be counter-productive.

This piece of findings (i.e., negative contribution of Chinese (L1) orthographic skills to English (L2) word reading) is somewhat discrepant from the findings reported by Wang et al. (2005), who investigated the transfer of phonological and orthographic skills in ChineseEnglish bilingual children. In their study, it was found that orthographic skills in Chinese did 
not predict English word reading. It is possible that Hong Kong elementary school children while developing their phonological awareness in English (L2) would also use some Chinese tactics, such as the whole word method, to assist their learning to read some novel English words. However, the attempt to use a Chinese strategy, whether implicitly or explicitly, may interfere with English word learning as those strategies may not be relevant for learning another orthography that has different orthographic rules and script-sound relationship. In the study of Wang et al. (2005), their participants were Chinese immigrant children who were reported not to have any English proficiency problems. It is believed that their English phonological skills are to be much advanced than the participants' in the present study. It is possible that ESL learners having achieved high level of English proficiency were less likely to use orthographic strategies in L1 to assist their English word reading given their well developed fundamental English phonological skills. In sum, the present findings appear to support that alphabetic strategies are more effective for ESL learning than are Chinese/logographic strategies.

\section{Transfer of Phonological Skills}

Results of the present study have shown that: (a) Chinese rhyme detection was correlated significantly to English rhyme detection and English initial phoneme deletion; (b) Chinese rhyme detection did account for a significant unique amount of variance in the prediction of English initial phoneme deletion; and (c) English initial phoneme deletion and English rhyme detection predicted a significant unique amount of variance in English (L2) word reading, but Chinese rhyme detection did not. These findings provide support only for the possible transfer of phonological skills in Chinese (L1) to phonological skills in English (L2), but not for the transfer of phonological skills in Chinese (L1) to English (L2) word reading. That is, rhyme awareness in Chinese (L1) facilitates the development of phonemic 
awareness in English (L2), in which the latter is an essential skill directly predicting ESL learning.

The piece of findings goes beyond previous research findings on the crossorthography transfer of phonological skills, in which phonological skills transfer exists not just at the parallel subsyllabic levels but also between the subsyllabic level of Chinese (L1) and the phonemic level of English (L2). As mentioned above, previous studies on phonological skills transfer between Chinese and English only provide evidence to the transfer of phonological awareness at the parallel subsyllabic (rhyme) level (e.g., Gottardo et al., 2001; Huang \& Hanley, 1994; Pang, 2004). But in the present study, we find evidence to support that an individual's phonological skills in his native language may be a foundation for him to develop phonological skills in other languages (even the foreign language may be quite different from their native language, e.g., Chinese vs. English). However, it is noteworthy that the English initial phoneme deletion task may not be a perfect measure of full phonemic awareness. Future studies may consider the inclusion of other English phonemic tasks like nonword reading, and Chinese initial phoneme deletion task may also be used for comparison with English.

\section{Transfer of Rapid Automatized Naming Skill}

Results of the present study have shown that Chinese (L1) and English (L2) rapid automatized naming skills were highly associated with each other, and both of them significantly predicted Chinese (L1) word reading, but did not predict ESL learning. These findings confirm the expectation that rapid automatized naming skills in Chinese (L1) and English (L2) share some common underlying skills that make transfer possible between them. Rapid naming skills may reflect a person's general processing speed, visual-verbal learning and processing, and phonological retrieval. These skills in a person's native language is likely transferable to learning the second language as found in the present study. 
Rapid automatized naming skills in Chinese (L1) and English (L2) were found to be highly correlated, yet Chinese (L1) and English (L2) rapid naming skills only predicted Chinese (L1) word reading significantly, but did not predict English (L2) word reading. It is worthwhile to further investigate if rapid naming would predict reading of familiar and high frequency English words, as well as if a minimum threshold of L2 word reading proficiency has to be reached for rapid automatized naming to be a sensitive predictor of L2 word reading.

\section{Educational Implications and Conclusion}

The present study adds further evidence for the phonological transfer between learning to read Chinese (L1) and English (L2), with the evidence that phonological transfer exists not only at the parallel rhyme levels, but also across the Chinese rhyme level to the English phonemic level. Findings also support phonemic processing skills to be important in learning to read English as a second language. These findings point to the education implications on early phonological and phonemic training in Chinese (L1) and English (L2) that benefits Hong Kong elementary school children in their ESL development.

In addition, in the present study, the use of Chinese orthographic skills were found to predict negatively their English (L2) word reading performance among early Cantonesespeaking ESL learners in Hong Kong. It is suggested that Hong Kong elementary school children with developing English phonological skills may rely on some Chinese (L1) learning tactics to help learning to read English (L2). However, the present findings suggest that this may not be effective. Therefore, systematic teaching of English letter patterns together with the phonics approach may benefit Hong Kong early ESL learners. Further investigation is needed for better understanding of the effects of other environmental and language factors (e.g., home language and literacy environment, and general oral English proficiency) on ESL learning. 


\section{References}

Akamatsu, N. (1999). The effects of first language orthographic features on word recognition processing in English as a second language. Reading and Writing: An Interdisciplinary Journal, 11, 381-403.

Akita, K. \& Hatano, G. (1999). Learning to read and write in Japanese. In M. Harris, \& G. Hatano, (Eds.), Learning to read and write: A cross-lingustic perspective. London: Cambridge University Press.

Bernhardt, E. B. (1991). Reading development in a second language: Theoretical, empirical, and classroom perspectives. Norwood, NJ: Ablex.

Bowers, P. G. (1993). Text reading and rereading: Determinants of fluency beyond word recognition. Journal of Reading Behavior, 25, 133-153.

Bowers, P. G. \& Swanson, L. B. (1991). Naming speed deficits in reading disability: Multiple measures of a singular process. Journal of Experimental Child Psychology, 51, 195219.

Bowers, P. G. \& Newby-Clark, E. (2002). The role of naming speed within a model of reading acquisition. Reading and Writing: An Interdisciplinary Journal, 15, 109-126.

Carillo, M. (1994). Development of phonological awareness and reading acquisition: A study in Spanish language. Reading and Writing: An Interdisciplinary Journal, 6, 279-298.

Carr, T. H. \& Levy, B. A. (Eds.) (1990). Reading and its development: Component skills approaches. New York: Academic Press.

Casalis, S. \& Louis-Alexandre, M. F. (2000). Morphological analysis, phonological analysis and leaning to read French: A longitudinal study. Reading and Writing: An Interdisciplinary Journal, 12, 303-335.

Chall, J. S. (1983). Stages of reading development. New York: McGraw-Hill. 
Cho, J. R. \& Chen, H. C. (1999). Orthographic and phonological activation in the semantic processing of Korean Hanja and Hangul. Language and Cognitive Processes, 14(56), 481-502.

Chow, B. W.-Y., McBride-Chang, C., \& Burgess, S. (2005). Phonological processing skills and early reading abilities in Hong Kong Chinese kindergarteners learning to read English as a second language. Journal of Educational Psychology, 97, 81-87.

Comeau, L., Cormier, P., Grandmaison, E., \& Lacroix, D. (1999). A longitudinal study of phonological processing skills in children learning to read in a second language. Journal of Educational Psychology, 91, 29-43.

Cossu, G., Shankweiler, D., Liberman, I. Y., Tola, G., \& Katz, L. (1988). Awareness of phonological segments and reading ability in Italian children. Applied Psycholinguistics, 9, 1-16.

Cummins, J. (1991). Interdependence of first- and second-language proficiency in bilingual children. In E. Bialystok (Ed.), Language processing in bilingual children (pp. 70-89). Cambridge, England: Cambridge University Press.

D'Angiulli, A., Siegel, L. S., \& Serra, E. (2001). The development of reading in Italian and English in bilingual children. Applied Psycholinguistics, 22, 479-507

Durgunoglu, A. Y., Nagy, W. W., \& Hancin-Bhatt, B. J. (1993). Cross-language transfer of phonemic awareness. Journal of Educational Psychology, 85, 453-465.

Ehri, L. C. (1995). Phases of development in learning to read words by sight. Journal of Research in Reading, 18, 116-125.

Ehri, L. C. (1999). Phases of development in learning to read words. In J. Oakhill \& R. Beard (Eds.), Reading development and the teaching of reading: A psychological perspective (pp. 79-108). Oxford: Blackwell Publishers. 
Ehri, L. C., Nunes, S. R., Schuster, B. V., Yaghoub-Zadeh, Z. \& Shanahan, T. (2001). Phonemic awareness instruction helps children learn to read: Evidence from the National Reading Panel's meta-analysis. Reading Research Quarterly, 36, 250-287.

Fitzgerald, J. (1995). English-as-a-second-language learners' cognitive reading processes: A review of research in the United States. Review of Educational Research, 65, 145-190.

Frith, U. (1985). Beneath the surface of development dyslexia. In K. E. Patterson, J. C. Marshall \& M. Coltheart (Eds.), Surface dyslexia. Hillsdale, NJ: Erlbaum.

Geva, E. \& Ryan, E. B. (1993). Linguistic and memory correlates of academic skills in first and second languages. Language Learning, 43, 5-42.

Geva, E. \& Siegel, L. S. (2000). Orthographic and cognitive factors in the concurrent development of basic reading skill in two languages. Reading and Writing: An. Interdisciplinary Journal, 12, 1-30.

Geva, E., Wade-Woolley, L., \& Shany, M. (1997). The development of reading efficiency in a first and second language. Scientific Studies of Reading, 1, 119-144.

Goswami, U. (1990). Phonological priming and orthographic analogies in reading. Journal of Experimental Child Psychology, 49, 323-340.

Goswami, U. (2000). Phonological and lexical processes. In Barr, R., Kamil, M., Mosenthal, P., \& Pearson, D. (Eds.), Handbook of Reading Research, Vol. 3, (pp. 251-268). London: Lawrence Erlbaum Associates.

Goswami, U. \& Bryant, P. (1990). Phonological skills and learning to read. London: Lawrence Erlbaum Associates.

Gottardo, A. (2002). The relationship between language and reading skills in bilingual Spanish-English speakers. Topics in Language Disorders, 22, 46-70.

Gottardo, A., Yan, B., Siegel, L., \& Wade-Woolley, L. (2001). Factors related to English reading performance in children with Chinese as a first language: More evidence of 
cross-language transfer of phonological processing. Journal of Educational Psychology, 93, 530-542.

Hanley, J. R., Tzeng, O. J.-L., \& Huang, H. S. (1999). Learning to read Chinese. In M. Harris, \& G. Hatano, (Eds.), Learning to read and write: A cross-lingustic perspective (pp. 173-195). London: Cambridge University Press.

Ho, C. S.-H. \& Bryant, P. (1997a). Learning to read Chinese beyond the logographic phase. Reading Research Quarterly, 32, 276-289.

Ho, C. S.-H. \& Bryant, P. (1997b). Phonological skills are important in learning to read Chinese. Developmental Psychology, 33, 946-951.

Ho, C. S.-H., Chan, D. W.-O., Tsang, S.-M., \& Lee, S.-H. (2000). The Hong Kong Test of Specific Learning Difficulties in Reading and Writing. Hong Kong: Hong Kong Specific Learning Difficulties Research Team.

Ho, C. S.-H., Chan, D. W.-O., Tsang, S.-M., \& Lee, S.-H. (2002). The cognitive profile and multiple deficit hypothesis in Chinese developmental dyslexia. Developmental Psychology, 38, 543-553.

Ho, C. S.-H., Chan, D. W.-O., Tsang, S.-M., Lee, S.-H., \& Luan, V. H. (2004). Cognitive profiling and preliminary subtyping in Chinese developmental dyslexia. Cognition, 91, 43-75.

Ho, C. S.-H. \& Lai, D. N.-C. (1999). Naming speed deficits and phonological memory deficits in Chinese developmental dyslexia. Learning and Individual Differences, 11, $173-186$.

Ho, C. S.-H., Wong, W.-L., \& Chan, W.-S. (1999). The use of orthographic analogies in learning to read Chinese. Journal of Child Psychology and Psychiatry, 40, 393-403.

Ho, C. S.-H., Yau, P. W.-Y., \& Au, A. (2003). Development of orthographic knowledge and its relationship with reading and spelling among Chinese kindergarten and primary 
school children. In C. McBride-Chang \& H. C. Chen (Eds.), Reading development in Chinese children (pp. 51-72). Westport: Praeger Publishers.

Hu, C. F. \& Catts, H. W. (1998). The role of phonological processing in early reading ability: What we can learn from Chinese. Scientific Studies of Reading, 2, 55-79.

Huang, H. S. \& Hanley, J. R. (1994). Phonological awareness and visual skills in learning to read Chinese and English. Cognition, 54, 73-98.

Kail, R., \& Hall, L K. (1994). Processing speed, naming speed, and reading. Developmental Psychology, 30, 949-954.

Leong, C. K. \& Joshi, R. M. (1997). Relating phonologic and orthographic processing to learning to read and spell. In C. K. Leong \& R. M. Joshi (Eds.), Cross-language studies of learning to read and spell: phonologic and orthographic processing (pp. 129). London: Kluwer Academic Publishers.

Lepola, J., Poskiparta, E., Laakkonen, E., \& Niemi, P. (2005). Development of and relationship between phonological and motivational processes and naming speed in predicting word recognition in grade 1. Scientific Study of Reading, 9, 367-399.

Lundberg, I. (1994). Reading difficulties can be predicted and prevented: A Scandinavian perspective on phonological awareness and reading. In C. Hulme \& M. Snowling (Eds.), Reading development and dyslexia (pp. 180-199). London: Whurr Publishers.

Manis, F. R., Doi, L. M., \& Bhadha, B. (2000). Naming speed, phonological awareness, and orthographic knowledge in second graders. Journal of Learning Disabilities, 33, 325$333 \& 374$.

Manis, F. R., Seidenberg, M. S., \& Doi, L. M. (1999). See Dick RAN: Rapid naming and the longitudinal prediction of reading subskills in first and second graders. Scientific Study of Reading, 3, 129-157. 
Mann, V. (2000). Introduction to special issue on morphology and the acquisition of alphabetic writing systems. Reading and Writing: An Interdisciplinary Journal, 12, 143-147.

McBride-Chang, C. \& Ho, C. S.-H. (2000). Naming speed and phonological awareness in Chinese children: Relations to reading skills. Journal of Psychology in Chinese Societies, 1, 93-108.

McBride-Chang, C. \& Ho, C. S.-H. (2005). Predictors of beginning reading in Chinese and English: A 2-year longitudinal study of Chinese kindergartners. Scientific Studies of Reading, 9, 117-144.

McBride-Chang, C., \& Treiman, R. (2003). Use of letter names and letter sounds in learning to read English among young Hong Kong Chinese children. Psychological Science, $14,138-143$.

Oney, B. \& Durgunoglu, A. Y. (1997). Beginning to read in Turkish: A phonologically transparent orthography. Applied Psycholinguistics, 18, 1-15.

Pang, E. S.-H. (2004). Cross-linguistic transfer of reading skills in bilingual children. Dissertation Abstracts International, 64 (11), 3995. (UMI No. AAT3111777)

Perfetti, CA (1984). Reading acquisition and beyond: Decoding includes cognition. American Journal of Education, 92, 40-60.

Rack, J. P., Snowling, M. J., \& Olson, R. K. (1992). The nonword reading deficit in developmental dyslexia: A review, Reading Research Quarterly, 27, 28-53.

Sebastian-Galles, N. \& Parreno-Vacchiano, A. (1995). The development of analogical reading in Spanish. Reading and Writing: An Interdisciplinary Journal, 11, 281-299.

Shankweiler, D. \& Fowler, A. E. (2004). Questions people ask about the role of phonological processes in learning to read. Reading and Writing: An Interdisciplinary Journal, 17, 483-515. 
So, D., \& Siegel, L. S. (1997). Learning to read Chinese: Semantic, syntactic, phonological and working memory skills in normally achieving and poor Chinese readers. Reading and Writing: An Interdisciplinary Journal, 9, 1-21.

Sprenger-Charolles, L., Siegel, L. S., \& Bonnet, P. (1998). Reading and spelling acquisition in French: the role of phonological mediation and orthographic factors. Journal of Experimental Child Psychology, 68, 134-65.

Sprenger-Charolles, L., Siegel, L. S., Bechennec, D., \& Serniclaes, W. (2003). Development of phonological and orthographic processing in reading aloud, in silent reading, and in spelling: A four-year longitudinal study. Journal of Experimental Child Psychology, 84, 194-217.

Torgesen, J. K. (1999). Phonologically based reading disabilities: Toward a coherent theory of one kind of learning disability. In R. J. Sternberg \& L. Spear-Swerling (Eds.), Perspectives on Learning Disabilities (pp. 106-135). New Haven: Westview Press.

Vellutino, F. R., Scanlon, D. M., \& Tanzman, M. S. (1994). Components of reading ability: Issues and problems in operationalizing word identification, phonological coding, and orthographic coding. In G.R. Lyon (Ed.). Frames of reference for the assessment of learning disabilities: New views on measurement issues (pp. 279-332). Baltimore, MD: Brookes.

Wagner, R. K. \& Barker, T. A. (1994). The development of orthographic processing ability. In V. W. Berninger (Ed.), The varieties of orthographic knowledge 1: Theoretical and developmental issues (pp. 243-276). Dordrecht, The Netherlands: Kluwer Academic Publishers.

Wagner, R. K., \& Torgesen, J. K. (1987). The nature of phonological processing and its causal role in the acquisition of reading skills. Psychological Bulletin, 101, 192-212. 
Wang, M, Park, Y.-J., \& Lee, K.-R. (2006). Korean-English biliteracy acquisition: Crosslanguage phonological and orthographic transfer. Journal of Educational Psychology, $98,148-158$.

Wang, M., Perfetti, C. A., \& Liu, Y. (2005). Chinese-English biliteracy acquisition: Crosslanguage and writing system transfer. Cognition, 97, 67-88.

Wimmer, H. \& Hummer, P. (1990). How German speaking first graders read and spell: Doubts on the importance of the logographic stage. Applied Psycholinguistics, 11, $349-368$.

Wolf, M. \& Bowers, P. (1999). The "Double-Deficit Hypothesis" for the developmental dyslexias. Journal of Educational Psychology, 91, 1-24.

Wolf, M., Vellutino, F., \& Gleason, J. B. (1998). A psycholinguistic account of reading. In Gleason and N. Bernstein Ratner, Psycholinguistics (2nd Edition). New York: Harcourt Brace.

Yeung, P. S. (2006). Learning to read and spell in English among Chinese English-as-asecond-language learners in Hong Kong. Unpublished doctoral dissertation, University of Hong Kong, Hong Kong SAR China.

Yopp, H. K. (1992). Developing phonemic awareness in young children. The Reading Teacher, 45, 696-703. 
Table 1

Means, Standard Deviations, and Reliability Coefficients of Various Tasks

\begin{tabular}{lccc}
\hline \multicolumn{1}{c}{ Task (max. score) } & Mean & SD & $\begin{array}{c}\text { Spilt-half or test- } \\
\text { retest reliability }\end{array}$ \\
\hline Chinese word reading (65) & 51.94 & 9.82 & $\mathrm{~S}$ \\
Chinese rhyme detection (17) & 10.87 & 2.87 & .70 \\
Chinese lexical decision (60) & 50.62 & 5.25 & $\mathrm{~S}$ \\
Chinese picture rapid naming (in & 36.76 & 7.26 & .91 \\
seconds) & & & .96 \\
English word reading (65) & 18.94 & 10.20 & .65 \\
English rhyme detection (18) & 12.28 & 2.71 & .96 \\
$\begin{array}{l}\text { English initial phoneme deletion } \\
\text { (20) }\end{array}$ & 3.89 & 5.12 & .61 \\
English lexical decision (17) & 8.06 & 2.62 & .89 \\
$\begin{array}{l}\text { English picture rapid naming (in } \\
\text { seconds) }\end{array}$ & 44.60 & 10.89 & \\
\hline
\end{tabular}

$\mathrm{S}$ - Standardized measure with good reported reliability. 
Table 2

$\underline{\text { Partial Correlation Coefficents among Chinese and English Literacy and Cognitive Tasks }}$ after Controlling for the Effects of Age and IQ

\begin{tabular}{lcccccccc}
\hline \multicolumn{1}{c}{ Task } & 1 & 2 & 3 & 4 & 5 & 6 & 7 & 8 \\
\hline 1. Chinese Word Reading & - & & & & & & \\
2. Chinese Rhyme Detection & .17 & - & & & & & \\
3. Chinese Lexical Decision & -.26 & -.09 & - & & & & & \\
4. Chinese Rapid Naming & $-.44^{* *}$ & -.08 & .13 & - & & & \\
5. English Word Reading & $.58^{* * *}$ & $.52^{* * *}$ & -.27 & $-.28^{*}$ & - & & & \\
6. English Rhyme Detection & $.34^{*}$ & $.31 *$ & .26 & -.14 & $.34 *$ & - & & \\
7. English Phoneme Deletion & $.32 *$ & $.48^{* * *}$ & -.04 & $-.29 *$ & $.78^{* * *}$ & $.34 *$ & - & \\
8. English Lexical Decision & .26 & .24 & .00 & -.02 & $.29 *$ & .27 & .22 & - \\
9. English Rapid Naming & $-.46^{* *}$ & .04 & .08 & $.67 * * *$ & -.26 & .04 & -.24 & -.08 \\
\hline
\end{tabular}

$* \mathrm{p}<.05 . \quad * * \mathrm{p}<.01 . \quad * * * \mathrm{p}<.001$ 
Table 3

Hierarchical Regression Analyses Predicting Chinese Word Reading Using Chinese and English Cognitive Tasks

\begin{tabular}{ccccc}
\hline \multicolumn{1}{c}{ Step/Variable } & $\beta$ & Total $\mathrm{R}^{2}$ & $\mathrm{R}^{2}$ Change & F Change \\
\hline Step 1: Age, & -.05 & .13 & .13 & $3.77^{*}$ \\
IQ & $.36^{*}$ & & & \\
Step 2: Chinese rhyme detection, & .17 & .21 & .08 & 2.36 \\
Chinese lexical decision & -.23 & & & \\
Step 3: Chinese rapid naming & $-.38^{* *}$ & .35 & .14 & $10.04^{* *}$ \\
Step 4: English lexical decision, & .21 & .41 & .06 & 2.29 \\
English initial phoneme deletion & .16 & & & \\
Step 5: English rhyme detection & $.30^{*}$ & .47 & .06 & $5.37^{*}$ \\
Step 6: English rapid naming & $-.35^{*}$ & .53 & .06 & $5.58^{*}$ \\
\hline
\end{tabular}

$* \mathrm{p}<.05 . \quad * * \mathrm{p}<.01 . \quad * * * \mathrm{p}<.001$. 
Table 4

Hierarchical Regression Analyses Predicting English Word Reading Using English and

$\underline{\text { Chinese Cognitive Tasks }}$

\begin{tabular}{ccccc}
\hline \multicolumn{1}{c}{ Step/Variable } & $\beta$ & Total $\mathrm{R}^{2}$ & $\mathrm{R}^{2}$ Change & F Change \\
\hline Step 1: Age, & -.16 & .11 & .11 & 3.09 \\
IQ & $.29 *$ & & & \\
Step 2: English rapid naming, & -.23 & .23 & .12 & $3.57^{*}$ \\
English lexical decision & .26 & & & \\
Step 3: English rhyme detection & $.29^{*}$ & .31 & .07 & $5.09^{*}$ \\
Step 4: English initial phoneme deletion & $.72^{* * *}$ & .67 & .37 & $51.67^{* * *}$ \\
Step 5: Chinese rhyme detection, & .20 & .69 & .02 & 1.44 \\
Chinese rapid naming & -.00 & & & \\
Step 6: Chinese lexical decision & $-.26^{* *}$ & .75 & .06 & $9.95^{* *}$ \\
\hline
\end{tabular}

$* \mathrm{p}<.05 . \quad * * \mathrm{p}<.01 . \quad * * * \mathrm{p}<.001$ 
Table 5

Hierarchical Regression Analyses Predicting English Initial Phoneme Deletion Using Chinese $\underline{\text { Rhyme Detection }}$

\begin{tabular}{ccccc}
\hline \multicolumn{1}{c}{ Step/Variable } & $\beta$ & Total $\mathrm{R}^{2}$ & $\mathrm{R}^{2}$ Change & F Change \\
\hline Step 1: Age, & -.22 & .12 & .12 & $3.44^{*}$ \\
IQ & $.27^{*}$ & & & \\
Step 2: English rhyme detection & $.32^{*}$ & .22 & .10 & $6.26^{*}$ \\
Step 3: Chinese rhyme detection & $.48^{* *}$ & .36 & .14 & $10.39^{* *}$ \\
\hline
\end{tabular}

$* \mathrm{p}<.05 . \quad * * \mathrm{p}<.01 . \quad * * * \mathrm{p}<.001$ 